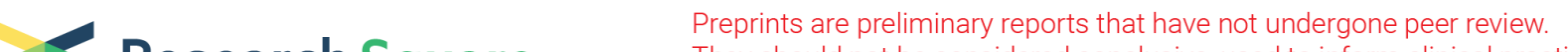 $\begin{array}{ll}\text { Research Square } & \begin{array}{l}\text { They should not be considered conclusive, used to inform clinical practice, } \\ \text { or referenced by the media as validated information. }\end{array}\end{array}$
}

\section{4-Bromobenzohydrzide Derivatives as Potent a- amylase Enzyme Inhibitors; Synthesis, in Vitro and in Silico Studies}

Momin Khan ( $\nabla$ mominkhan@awkum.edu.pk)

Abdul Wali Khan University Mardan https://orcid.org/0000-0003-0936-5025

Faima Alam

Abdul Wali Khan University Mardan

Muhammad Ateeq

Abdul Wali Khan University Mardan

Abdul Wadood

Abdul Wali Khan University Mardan

Mahboob Ali

Abdul Wali Khan University Mardan

Sana Shah

Abdul Wali Khan University Mardan

Aftab Alam

Abdul Wali Khan University Mardan

Muhammad Yousaf

Abdul Wali Khan University Mardan

Ahmad Ali

Sarhad University of Science and Information Technology Ring Road Campus

\section{Research Article}

Keywords: Diabetes mellitus, a-amylase, 4-bromobenzoic acid, 4-bromobenzohydrzide, SAR

Posted Date: February 16th, 2022

DOI: https://doi.org/10.21203/rs.3.rs-1337627/v1

License: (c) (i) This work is licensed under a Creative Commons Attribution 4.0 International License. Read Full License 


\section{Abstract}

Current study is focused to synthesize 4-Bromobenzohydrzide detivatives (1-29) and were examined for a-amylase enzyme inhibitory potential at various concentrations. 4-Bromobenzoic acid hydrzide detivatives (1-29) were synthesized via three stpers reaction from 4-bromobenzoic acid. Esterification was done by refluxing in $\mathrm{MeOH}$ for $2 \mathrm{hr}$ in the presence of of concentrated $\mathrm{H} 2 \mathrm{SO} 4$ till dissolution. In second step methyl 4-bromobenzoate and hydrazine hydrate in excess (1:5) was refluxed in methanol. 4Bromobenzohydrazide hydrazones were synthesized by the condensation reaction of substituted aryl aldehydes and 4-bromobenzohydrazide in the presence of ethanol and glacial acetic acid. All synthesized derivatives demonstrated good inhibitory activities in the range of IC $50=0.217 \pm 0.012-5.5 \pm 0.019$ as compared to standard Acarbose having IC50 $=1.34 \pm 0.019$. Out of twenty nine (29) derivatives, only five (05) compounds $238,24,9$, and 13 showed less activity than the standard. Results of the enzyme inhibition its self showed that the activity of this library is due to the core structure. The slightly changes in activity is might be due to the different substitutions and position of the substitution. Furthermore; molecular docking study was performed in order to explore the possible binding mode of the synthesized compounds against a-amylase enzyme.

\section{Introduction}

A metabolic syndrome known as diabetes mellitus is related to the impairment of endocrinal system. These endocrinal complicationsresulted in hyperglycemia or highblood sugar level which maydue to deficiency of insulin secretion, or insufficient activity.Among the various approaches in the treatment of diabetes, one is to reduce the high blood sugar level by inhibiting the hydrolysis of enzymes such as $a$ amylase and $a$-glucosidase [1, 2]. $a$-Amylase( $a$-1,4-glucan-4-glucanohydrolases, EC. 3.2.1.1) secreted from pancreas, is present in the tissues of mammals, plants, and microorganisms. Starch breakdown into glucose and maltose by the help of hydrolyzing enzymea-amylase in the small intestine [3, 4]. However, high level of this enzyme may cause increased blood sugar level, leading to diabetes [5]. Therefore, in the treatment of diabetes mellitus, $\alpha$-amylase inhibitors are considered to be an important target molecule [6-11]. Commercially $a$-amylase inhibitors are voglibose, and acarbose in order to treat diabetes mellitus but these drugs have some adverse effect such as diarrhea and flatulence [12].

Benzohydrazides and hydrazones are reported to possess a wide variety of biological activities like antiglycation [19-22], antioxidant [23-25], antileishmanial [26], antibacterial [27], urease inhibition [28], antifungal [29], antitumor [30] and anticonvulsant [31]. Benzothiazole Schiff bases have also been reported with various biological activities [32].

This study was aimed to synthesize a new series of 4-bromobenzohydrazide derivatives with $\alpha$-amylase inhibitory activities. Herein, we report the synthesis, Characterization, and in vitro $a$-amylase inhibitory potentials

\section{Resuilt And Discussion}


4-Bromobenzoic acid hydrzide detivatives (1-29) were synthesized via three stpers reaction from 4bromobenzoic acid. Esterification was done by refluxing in $\mathrm{MeOH}$ for $2 \mathrm{hr}$ in the presence of of concentrated $\mathrm{H}_{2} \mathrm{SO}_{4}$ till dissolution. Sodium bicarbonate solution was added to cooled reaction mixture till the bubble formation stopped. The products were filtered and washed with water thoroughly [33]. In second step methyl 4-bromobenzoate and hydrazine hydrate in excess (1:5) was refluxed in methanol. After cooling, the reaction mixture was transferred to ice cold water. Recrystallization was done via ethanol [34]. 4-Bromobenzohydrazide hydrazones were synthesized by the condensation reaction of substituted aryl aldehydes and 4-bromobenzohydrazide in the presence of ethanol and glacial acetic acid with continuous stirring till completion of reaction. For the confirmation of newly synthesized 4bromobenzohydrazide derivatives (1-29) spectroscopic techniques such as ${ }^{1} \mathrm{H}-\mathrm{NMR}$ and El-MS were performed. All compounds are new and previously unreported.

The ${ }^{1} \mathrm{H}$-NMR spectral data and El-MS confirm molecular mass of synthesized derivatives were in good agreements with $\pm 0.2-0.6 \%$ with actual mass of compounds due to presence of different isotopes.

SEM = Standard error mean; acarbose = Standard for a-amylase inhibition activity

\section{Structure-activity relationship (SAR)}

All synthesized hydrazide derivatives 1-29 were screened for in vitro urease inhibition activity. All compounds 1-29 showed excellent activity. Where $\mathrm{IC}_{50}$ values of synthesized derivatives ranges from $0.217 \pm 0.12 \mu \mathrm{M}$ to $5.5 \pm .019 \mu \mathrm{M}$ as compared to standard acarbose $\left(\mathrm{IC}_{50}=1.34 \pm 0.019 \mu \mathrm{M}\right)($ Table 1$)$. Majority synthesized derivatives $18\left(\mathrm{IC}_{50}=0.217 \pm 0.012 \mu \mathrm{M}\right), \mathbf{1 1}\left(\mathrm{IC}_{50}=1.02 \pm 0.071 \mu \mathrm{M}\right), 25\left(\mathrm{IC}_{50}=\right.$ $1.027 \pm 0.072 \mu \mathrm{M}), 26\left(I C_{50}=1.031 \pm 0.063 \mu \mathrm{M}\right), 2\left(I C_{50}=1.062 \pm 0.017 \mu \mathrm{M}\right), 10\left(I C_{50}=1.063 \pm\right.$ $0.067 \mu \mathrm{M}), 1\left(\mathrm{IC} \mathrm{C}_{50}=1.079 \pm 0.019 \mu \mathrm{M}\right), 12\left(\mathrm{IC}_{50}=1.089 \pm 0.023 \mu \mathrm{M}\right), 16\left(\mathrm{IC}_{50}=1.096 \pm 0.043 \mu \mathrm{M}\right), 19\left(\mathrm{IC}_{50}\right.$ $=1.1148 \pm 0.07 \mu \mathrm{M}), 27\left(\mathrm{IC}_{50}=1.117 \pm 0.092 \mu \mathrm{M}\right), \mathbf{4}\left(\mathrm{IC}_{50}=1.12 \pm 0.011 \mu \mathrm{M}\right), \mathbf{6}\left(\mathrm{IC}_{50}=1.12 \pm 0.019 \mu \mathrm{M}\right), \mathbf{5}$ $\left(\mathrm{IC}_{50}=1.126 \pm 0.037 \mu \mathrm{M}\right), 7\left(\mathrm{IC}_{50}=1.16 \pm 0.023 \mu \mathrm{M}\right), 17\left(\mathrm{IC}_{50}=1.217 \pm 0.012 \mu \mathrm{M}\right), \mathbf{3}\left(\mathrm{IC}_{50}=1.241 \pm\right.$ $0.039 \mu \mathrm{M}), 14\left(\mathrm{IC}_{50}=1.244 \pm 0.055 \mu \mathrm{M}\right), 22\left(\mathrm{IC} \mathrm{C}_{50}=1.245 \pm 0.022 \mu \mathrm{M}\right), 29\left(\mathrm{IC}_{50}=1.255 \pm 0.06 \mu \mathrm{M}\right), 28$ $\left(\mathrm{IC}_{50}=1.262 \pm 0.087 \mu \mathrm{M}\right), 15\left(\mathrm{IC}_{50}=1.266 \pm 0.04 \mu \mathrm{M}\right), 20\left(\mathrm{IC}_{50}=1.266 \pm 0.04 \mu \mathrm{M}\right)$ and $21\left(\mathrm{IC}_{50}=1.307 \pm\right.$ $0.019 \mu \mathrm{M})$ showed excellent activity better than standard. Out of twenty nine (29) derivatives, only five (05) compounds $23\left(\mathrm{IC}_{50}=1.51 \pm 0.028 \mu \mathrm{M}\right), \mathbf{8}\left(\mathrm{IC}_{50}=1.569 \pm 0.033 \mu \mathrm{M}\right), \mathbf{2 4}\left(\mathrm{IC}_{50}=1.61 \pm 0.061 \mu \mathrm{M}\right), \mathbf{9}$ $\left(\mathrm{IC}_{50}=3.53 \pm 0.062 \mu \mathrm{M}\right)$, and $13\left(\mathrm{IC}_{50}=5.5 \pm 0.019 \mu \mathrm{M}\right)$ showed less activity than the standard. Results of the enzyme inhibition its self showed that the activity of this library is due to the core structure. The slightly changes in activity is might be due to the different substitutions and position of the substitution.

In conclusion; Results of the a-amylase enzyme inhibition activity demonstrated that core skeleton of the library is responsible for the activity; furthermore slightly variation in activity might be due to the nature and position of the substituents. For detail insight confirmations of the bonding sights with enzyme in silico study were also performed.

Molecular docking study: 
Molecular docking study was performed in order to explore the possible binding mode of the synthesized compounds against a-amylase enzyme. Generally, we have observed that the enlisted compounds possess different substituted groups, i.e., some of the compounds possess electron-donating group, while others have electron-withdrawing group at different quantity and attachment position.

Interestingly, we have observed that the compounds bearing with-drawing group tremendously enhance the enzymatic activity, while bearing donating group also participating in the enhancement of enzymatic activity. Comparing the enhancement role in activity of both groups, we have found that compounds bearing withdrawing groups showed more potency than donating groups. We have also noticed that the position of attachment of the substituting groups also affecting the enzymatic activity, in the case of comparing compound 18 (at -ortho) and 11 (at -ortho and-para).

Molecular docking results reveal that all the compounds found well-interacted with active site residues of the targeted enzyme, the interactive residues might play a vital role in enhancing or reducing the activity of the enzyme. Fig. 1A showing the cartonic representation of the enzyme structure. While, narrow downing the enlisted compounds, we have found most potent compounds, including compound 18 (ranked 1st), $\mathbf{1 1}$ (ranked 2nd), and $\mathbf{2 7}$ (ranked 3rd) in the series, which mainly showed significant interactions with the active site residues.

In the case of docking result for ranked 1 st compound revealed side chain acceptor and pi-stacking interactions with residue Asn481 and Ser482 (Fig. 1B). The high potency of this compound might be due to the strong magnitude and quantity of the withdrawing group, which withdrawal some of the electronic density from the phi-system, interestingly, the mechanism might be like, once the withdrawal electron was further shared with the residues which interacted with this moiety, and hence the prospective moiety gain the stable environment, and this way, enhance the enzymatic activity. Comparing the activity of ranked 1 st with ranked 2 nd compound, which bearing same deactivated group $(\mathrm{Cl})$ with same quantity (i.e., di$\mathrm{Cl}$ ), showed different activity, the only difference found is the attachment position, i.e., ranked 1st (at ortho position), while the ranked 2 nd is at -ortho and -para position. The dramatic changes found in there activity might be due to the changing position of the attached group and might be due to the key interactions, where ranked 1st showed direct h-interaction, while 2nd ranked compound showed phistacking interactions (Fig. 1C for ranked 2nd compound).

Similarly, in case of compound bearing activating group also showed enough activity (Fig. 1D), but comparatively lower than the ranked 1 st and 2 nd compound whose hold withdrawing groups. Overall, we have observed that the compounds bearing withdrawing groups showed tremendous activity against the target enzyme. The results are in good agreement with the in-vitro experiment.

\section{Conclusion}

We have synthesized substituted 4-Bromobenzoic acid hydrazide derivatives 1-29 by three-step reactions from commercially available 4-bromobenzoic acid, hydrazine hydrate and aryl aldehyde. Twenty four compounds (1-7, 10-12, 14-22 and 25-29) were found to be more active than slandered acarbose. Out of 
twenty nine (29) derivatives, only five (05) compounds $23\left(\mathrm{IC}_{50}=1.51 \pm 0.028 \mu \mathrm{M}\right), 8\left(\mathrm{IC}_{50}=1.569 \pm\right.$ $0.033 \mu \mathrm{M}), 24\left(\mathrm{IC}_{50}=1.61 \pm 0.061 \mu \mathrm{M}\right), 9\left(\mathrm{IC}_{50}=3.53 \pm 0.062 \mu \mathrm{M}\right)$, and $13\left(\mathrm{IC}_{50}=5.5 \pm 0.019 \mu \mathrm{M}\right)$ showed less activity than the standard. Results of the enzyme inhibition its self showed that the activity of this library is due to the core structure. The slightly changes in activity is might be due to the different substitutions and position of the substitution. Furthermore; molecular docking study was performed in order to explore the possible binding mode of the synthesized compounds against a-amylase enzyme.

\section{Experimental}

\section{Materials and Methods}

Melting points were determined in an open capillary tubes with a Fisher John melting point apparatus and are uncorrected. NMR experiments were performed on Avance-Bruker ( 400 for $\left.{ }^{1} \mathrm{H}\right)$. The mass spectra were recorded by ESI-MS spectrometers (LCQ-DECA XP Plus, Thermo-Finnigan, San Diego, CA, USA). Thin layer chromatography (TLC) was performed on pre-coated silica gel aluminum plates (Kieselgel 60, 254, E. Merck, Germany). Chromatograms were visualized by UV visible light at $254 \mathrm{~nm}$ or iodine vapors.

Highly pure analytical grade chemicals and solvents were procured from (Darmstadt, Germany) and used as received. Porcine pancreatic $a$-amylase (PPA) (E.C.3.2.1.1), aryl benzaldehyde derivatives, and 4bromobenzohydrazide were purchased from Sigma (St Louis, MO, USA). Sodium hydroxide, soluble starch, maltose and other chemicals were obtained from Merck (Darmstadt, Germany).

\section{General procedure for the synthesis of new 4-bromobenzohydrzides.}

4-Bromobenzohydrzide (1-29) derivatives were synthesized through sequential reactions from 4Bromobenzoic acid. Esterification was done by refluxing in $\mathrm{MeOH}$ for $2 \mathrm{hr}$ in the presence of catalytic amount of concentrated $\mathrm{H}_{2} \mathrm{SO}_{4}$ till dissolution. Sodium bicarbonate solution was added to cooled reaction mixture till the bubble formation stopped. The products were filtered and washed with water thoroughly [33]. In second step methyl 4-bromobenzoate and hydrazine hydrate in excess (1:5) was refluxed in methanol. After cooling, the reaction mixture was transferred to ice cold water. Recrystallization was done via ethanol [34].

4-bromobenzohydrazides derivatives (1-29) were synthesized by reacting $0.1075 \mathrm{mg}$ of the 4bromobenzohydrazide with substituted aromatic aldehydes $20 \mathrm{ml}$ of methanol with addition of few drops of acetic acids in $100 \mathrm{ml}$ RB flask. The mixtures were refluxed for 1-2 hours. Completion of reaction was monitored by TLC. After the completion of reaction, products were washed, dried and the precipitates were characterized by ${ }^{1} \mathrm{HNMR}$ and El-MS spectra [35].

\section{Assay for alpha-amylase activity:}

According to reported method (Valaparla, 2010) for the a-amylase inhibitory activities in 96-well plate a mixture of $500 \mu \mathrm{L}$ of synthesized products of varying concentration $(1000,500,250,125,65.25 \mu \mathrm{g} / \mathrm{mL})$ 
are taken. $95 \mu \mathrm{L}$ of alpha- amylase (Sigma, $300 \mu \mathrm{M}$ ) in ethanol were taken in in a 96-well microliter plate and the incubation taken at $37^{\circ} \mathrm{C}$ for $30 \mathrm{~min}$ then $0.2 \mathrm{mM}$ phosphate buffer $(\mathrm{pH}=6.8)$ and $500 \mu \mathrm{L}$ of enzyme solution $(5 \mathrm{mg} / \mathrm{mL})$ for 20 min were carried out. After this step, further incubation at $37^{\circ} \mathrm{C}$ of 500 $\mu \mathrm{L}$ mixtures. Then dinitrosalicylic acid $((1 \mathrm{~mL})$ color reagent and mixture were boiled for $10 \mathrm{~min}$. Then cooled it and measure the absorbance at $540 \mathrm{~nm}$. By using the following formulas the percent inhibition of the results can be calculated as.

$\%$ Inhibition $=($ Absorbance Control - Absorbance Sample) $/$ Absorbance Control x 100 [36].

The $\mathrm{IC}_{50}$ values, concentration required to inhibit the $\alpha$-amylase activity by $50 \%$ were calculated by a nonlinear regression graph plotted between percentage inhibition ( $x$-axis) versus concentrations ( $y$-axis), using a Graph Pad Prism Software (Version 7).

Molecular operating environment (MOE)-Dock software suite was used to explore the binding mode of potent compounds in the active site of a-amylase enzyme. The 3D structural coordinates for all compounds were constructed using the MOE-Molecular Builder Module. For retrieving the 3D structural coordinates of a-amylase enzyme, we have used the PDB code 3BAJ in Protein Data Bank (www.rcsb.org). The detail protocol of molecular docking study has been described in our previous studies [37].

\section{Analytical physical and spectroscopic data of hydrazides:}

7.1: (E)-N'-(3-hydroxybenzylidene)-4-bromobenzohydrazide.

Molecular formula: $\mathrm{C}_{14} \mathrm{H}_{11} \mathrm{BrN}_{2} \mathrm{O}_{2}$, Molecular mass: 318. Yield: 93\%

${ }^{1} \mathrm{H}$ NMR $\left(400 \mathrm{MHz}, \mathrm{DMSO}-\mathrm{d}_{6}\right) \delta 11.20(1 \mathrm{H}, \mathrm{s}, \mathrm{NH}), 9.60(1 \mathrm{H}, \mathrm{s},-\mathrm{OH}), 8.40(1 \mathrm{H}, \mathrm{s},=\mathrm{CH}), 8.41(2 \mathrm{H}, \mathrm{d}, J=7.5$ $\mathrm{Hz}, \mathrm{H}-3 / 5), 8.14\left(1 \mathrm{H}, \mathrm{d}, J=8.0 \mathrm{~Hz}, \mathrm{H}-6^{\prime}\right), 8.01\left(1 \mathrm{H}, \mathrm{d}, J=8.0 \mathrm{~Hz}, \mathrm{H}-4^{\prime}\right), 7.80(2 \mathrm{H}, \mathrm{d}, J=7.5 \mathrm{~Hz}, \mathrm{H}-2 / 6), 7.76$ $\left(1 \mathrm{H}, \mathrm{s}, \mathrm{H}-2^{\prime}\right), 7.20\left(3 \mathrm{H}, \mathrm{t}, J=8.0 \mathrm{~Hz}, \mathrm{H}-5^{\prime}\right)$; El-MS $m / z$ (\% relative. abundance): $320\left(\mathrm{M}^{+2,} 98\right), 218\left(\mathrm{M}^{+}, 100\right)$, 155 (33), 78 (25); Anal. Calculated for $\mathrm{C}_{14} \mathrm{H}_{11} \mathrm{BrN}_{2} \mathrm{O}_{2}$ : (318) C, 53.02; $\mathrm{H}, 2.86 ; \mathrm{Br}, 25.20 \mathrm{~N}, 8.83 ; 0,10.09$. found: $\mathrm{C}, 53.01 ; \mathrm{H}, 2.87 ; \mathrm{N}, 8.82$.

7.2: (E)-N'-(4-hydroxy-3-methoxybenzylidene)-4-bromobenzohydrazide.

Molecular formula: $\mathrm{C}_{15} \mathrm{H}_{13} \mathrm{BrN}_{2} \mathrm{O}_{3}$, Molecular mass: 348. Yield $90 \%$

${ }^{1} \mathrm{H}$ NMR $\left(400 \mathrm{MHz}, \mathrm{DMSO}-\mathrm{d}_{6}\right) \delta 11.18(1 \mathrm{H}, \mathrm{s}, \mathrm{NH}), 10.57(1 \mathrm{H}, \mathrm{s},-\mathrm{OH}), 8.53(1 \mathrm{H}, \mathrm{s},=\mathrm{CH}), 18.4(2 \mathrm{H}, \mathrm{d}, \mathrm{J}=7.6$ $\left.\mathrm{Hz}, \mathrm{H}-2 / 6), 8.0\left(1 \mathrm{H}, \mathrm{d}, J=7.5 \mathrm{~Hz}, \mathrm{H}-/ 6^{\prime}\right), 7.5(2 \mathrm{H}, \mathrm{d}, J=8.0 \mathrm{~Hz}, \mathrm{H}-3 / 5), 7.76(1 \mathrm{H}, \mathrm{s}, \mathrm{H}-2)^{\prime}\right), 6.4(1 \mathrm{H}, \mathrm{d}, J=7.0$ $\left.\mathrm{Hz}, \mathrm{H}-/ 5^{\prime}\right)$; El-MS $m / z$ (\% relative. abundance): 350 ( $\left.\mathrm{M}^{+2}, 98\right), 248\left(\mathrm{M}^{+}, 100\right), 155$ (88), 123 (33); Anal. Calculated for $\mathrm{C}_{15} \mathrm{H}_{11} \mathrm{BrN}_{2} \mathrm{O}_{3}$ : (348): $\mathrm{C}, 51.90 ; \mathrm{H}, 3.19 ; \mathrm{Br}, 23.02 \mathrm{~N}, 8.07 ; 0,13.83$ : found: $\mathrm{C}, 51.92 ; \mathrm{H}, 3.20$; N, 8.08.

7.3: (E)-N'-(4-nitrobenzylidene)-4-bromobenzohydrazide. 
Molecular formula $\mathrm{C}_{14} \mathrm{H}_{10} \mathrm{BrN}_{3} \mathrm{O}_{3}$, Molecular mass 347 .Yield $88 \%$.

${ }^{1} \mathrm{HNMR}\left(400 \mathrm{MHz}, \mathrm{DMSO}-\mathrm{d}_{6}\right) \delta 12.19(1 \mathrm{H}, \mathrm{s}, \mathrm{NH}), 8.53(\mathrm{~s}, 1 \mathrm{H},=\mathrm{CH}), 8.41\left(2 \mathrm{H}, \mathrm{d}, J=8.8 \mathrm{~Hz}, \mathrm{H}-3^{\prime} / 5^{\prime}\right), 8.29$ $(2 \mathrm{H}, \mathrm{d}, J=8.0 \mathrm{~Hz}, \mathrm{H}-3 / 5), 8.14\left(2 \mathrm{H}, \mathrm{d}, J=8.8 \mathrm{~Hz}, \mathrm{H}-2^{\prime} / 6^{\prime}\right), 7.0(2 \mathrm{H}, \mathrm{d}, J=8.0 \mathrm{~Hz}, \mathrm{H}-2 / 6)$; El-MASS $\mathrm{m} / \mathrm{z}(\%$ relative. abundance): $349\left(\mathrm{M}^{+2,} 98\right), 247\left(\mathrm{M}^{+}, 100\right), 118(59), 76$ (76); Anal. Calculated for $\mathrm{C}_{14} \mathrm{H}_{10} \mathrm{~N}_{3} \mathrm{O}_{3}$ : (347) found: $\mathrm{C}, 48.30 ; \mathrm{H}, 2.90 ; \mathrm{N}, 12.07 ; \mathrm{O}, 13.79$ : found $\mathrm{C}, 48.32 ; \mathrm{H}, 2.92 ; \mathrm{N}, 12.09$.

7.4: (E)-N'-(2,3-dihydroxybenzylidene)-4-bromobenzohydrazide.

Chemical formula: $\mathrm{C}_{14} \mathrm{H}_{11} \mathrm{BrN}_{2} \mathrm{O}_{3}$, molecular mass: 334 , Yield 94\%.

${ }^{1} \mathrm{H}$ NMR $\left(400 \mathrm{MHz}, \mathrm{DMSO}-\mathrm{d}_{6}\right) \delta 12.18(1 \mathrm{H}, \mathrm{s}, \mathrm{NH}), 9.0(1 \mathrm{H}, \mathrm{s},-\mathrm{OH}), 8.53(1 \mathrm{H}, \mathrm{s},-\mathrm{OH}) 8.48(1 \mathrm{H}, \mathrm{s}=\mathrm{CH}), 8.0$ $(2 \mathrm{H}, \mathrm{d}, J=8.0 \mathrm{~Hz}, \mathrm{H}-3 / 5), 7.9(2 \mathrm{H}, \mathrm{d}, J=8.0 \mathrm{~Hz}, \mathrm{H}-2 / 6), 7.22(1 \mathrm{H}, \mathrm{s}, J=7.5 \mathrm{~Hz}, \mathrm{H}-6), 6.9(1 \mathrm{H}, \mathrm{s}, J=7.5 \mathrm{~Hz}$, $\left.\mathrm{H}-4^{\prime}\right), 6.81\left(1 \mathrm{H}, \mathrm{t}, J=7.5 \mathrm{~Hz}, \mathrm{H}-5^{\prime}\right)$; El-MASS $m / z$ (\% relative. abundance): $336\left(\mathrm{M}^{+2,} 98\right), 334\left(\mathrm{M}^{+}, 100\right), 183$ (65), 118 (39), 89 (78); Anal. Calculated for $\mathrm{C}_{14} \mathrm{H}_{11} \mathrm{~N}_{3} \mathrm{O}_{3}$ : (334): C, 48.30; $\mathrm{H}, 2.90 ; \mathrm{N}, 12.07 ; 0,13.79$ : found: C, 48.32; H, 2.91; N, 12.09 .

7.5: (E)-N'-(3,5-di-tert-butyl-4-hydroxybenzylidene)-4-bromobenzohydrazid.

Chemical formula: $\mathrm{C}_{22} \mathrm{H}_{27} \mathrm{BrN}_{2} \mathrm{O}_{2}$, molecular mass 430: Yield: $92 \%$

${ }^{1} \mathrm{H}$ NMR $\left(400 \mathrm{MHz}, \mathrm{DMSO}_{-\mathrm{d}}\right) \delta 12.18(\mathrm{~s}, 1 \mathrm{H}, \mathrm{NH}), 10.45(1 \mathrm{H}, \mathrm{s},-\mathrm{OH}), 8.51(1 \mathrm{H}, \mathrm{s}=\mathrm{CH}), 7.94(2 \mathrm{H}, \mathrm{d}, J=7.4$ $\mathrm{Hz}, \mathrm{H}-3 / 5), 7.71(2 \mathrm{H}, \mathrm{d}, J=7.4 \mathrm{~Hz}, \mathrm{H}-2 / 6), 7.52\left(2 \mathrm{H}, \mathrm{d}, J=1.2 \mathrm{~Hz}, \mathrm{H}-2^{\prime} / 6^{\prime}\right), 1.35\left(18 \mathrm{H}, \mathrm{s}, 2\left[-\mathrm{C}\left(\mathrm{CH}_{3}\right)_{3}\right]\right)$; ElMASS $m / z$ (\% relative. abundance): $332\left(\mathrm{M}^{+2}, 98\right), 330\left(\mathrm{M}^{+}, 100\right), 118(62), 76(83), 63(80) ;$ Anal. Calculated for $\mathrm{C}_{22} \mathrm{H}_{27} \mathrm{BrN}_{2} \mathrm{O}_{2}$ : (430): $\mathrm{C}, 61.26 ; \mathrm{H}, 6.31 ; \mathrm{Br}, 18.52 ; \mathrm{N}, 6.49 ; 0,7.42$, found $\mathrm{C}, 61.24 ; \mathrm{H}, 6.32 ; \mathrm{N}$, 6.48 .

7.6: (E)-N'-(3,4-dimethoxybenzylidene)-4-bromobenzohydrazide.

Chemical formula: $\mathrm{C}_{16} \mathrm{H}_{15} \mathrm{BrN}_{2} \mathrm{O}_{3}$, Molecular mass: 362 , Yield: $92 \%$

${ }^{1} \mathrm{H}$ NMR $\left(400 \mathrm{MHz}, \mathrm{DMSO}-\mathrm{d}_{6}\right) \delta, 12.18(1 \mathrm{H}, \mathrm{s}, \mathrm{NH}), 8.51(1 \mathrm{H}, \mathrm{s}=\mathrm{CH}), 8.40(2 \mathrm{H}, \mathrm{d}, J=7.6 \mathrm{~Hz}, \mathrm{H}-2 / 6), 8.27$ $(2 \mathrm{H}, \mathrm{d}, J=7.6 \mathrm{~Hz}, \mathrm{H}-3 / 5), 8.11\left(1 \mathrm{H}, \mathrm{s}, \mathrm{H}-2^{\prime} / 6^{\prime}\right), 7.5\left(1 \mathrm{H}, \mathrm{s}, \mathrm{H}-4^{\prime}\right), 7.0\left(6 \mathrm{H}, \mathrm{s},-\left(\mathrm{OCH}_{3}\right)_{2}\right)$; El-MS $\mathrm{m} / \mathrm{z}$ (\% relative. abundance) $364\left(\mathrm{M}^{+2}, 97\right), 362\left(\mathrm{M}^{+}, 100\right), 298$ (53), 223 (50), 77 (45); Anal. Calculated for $\mathrm{C}_{16} \mathrm{H}_{15} \mathrm{BrN}_{2} \mathrm{O}_{3}$ : (362): $\mathrm{C}, 52.91 ; \mathrm{H}, 4.16 ; \mathrm{Br}, 22.00 ; \mathrm{N}, 7.71 ; 0,13.22$ : found $\mathrm{C}, 53.01 ; \mathrm{H}, 4.03 ; \mathrm{N}, 7.70$.

7.7: (E)-N'-(4-bromo-3,5-dimethoxybenzylidene)-4-bromobenzohydrazide.

Chemical formula: $\mathrm{C}_{16} \mathrm{H}_{15} \mathrm{Br}_{2} \mathrm{~N}_{2} \mathrm{O}_{2}$, molecular mass: 440 : Yield $91 \%$.

${ }^{1} \mathrm{H}$ NMR $\left(400 \mathrm{MHz}, \mathrm{DMSO}-\mathrm{d}_{6}\right) \delta 12.12(1 \mathrm{H}, \mathrm{s} \mathrm{NH}), 8.55(1 \mathrm{H}, \mathrm{s}=\mathrm{CH}), 8.26(2 \mathrm{H}, \mathrm{d}, \mathrm{J}=7.6 \mathrm{~Hz}, \mathrm{H}-2 / 6), 8.10(2 \mathrm{H}$, $\mathrm{d}, J=7.6 \mathrm{~Hz}, \mathrm{H}-3 / 5), 7.4\left(2 \mathrm{H}, \mathrm{s}, \mathrm{Hz}, \mathrm{H}-2^{\prime} / 6^{\prime}\right), 7.0\left(6 \mathrm{H}, \mathrm{s},-\left(\mathrm{OCH}_{3}\right)_{2}\right)$; El-MS $m / z$ (\% relative. abundance): 444 
$\left(\mathrm{M}^{+4}, 48\right), 442\left(\mathrm{M}^{+2}, 100\right), 440\left(\mathrm{M}^{+}, 50\right), 410(54), 380(22), 360$ (94), 330 (40), 300 (52); Anal. Calculated for $\mathrm{C}_{16} \mathrm{H}_{15} \mathrm{Br}_{2} \mathrm{~N}_{2} \mathrm{O}_{2}$ : (442): $\mathrm{C}, 44 ; \mathrm{H}, 3 ; \mathrm{Br}, 36 ; \mathrm{N}, 6 ; \mathrm{O}, 1$, found: $\mathrm{C}, 44.03 ; \mathrm{H}, 3.06 ; \mathrm{N}, 6.07$.

7.8: (E)-N'-(2,3,4-trihydroxybenzylidene)-4-bromobenzohydrazide.

Chemical formula: $\mathrm{C}_{14} \mathrm{H}_{11} \mathrm{BrN}_{2} \mathrm{O}_{4}$, molecular mass: 350: Yield 94\%.

${ }^{1} \mathrm{H}$ NMR $\left(400 \mathrm{MHz}, \mathrm{DMSO}-\mathrm{d}_{6}\right) \delta 12.18(1 \mathrm{H}, \mathrm{s}, \mathrm{NH}), 10.56(3 \mathrm{H}, \mathrm{s},-\mathrm{OH}), 8.51(1 \mathrm{H}, \mathrm{s},=\mathrm{CH}), 8.29(2 \mathrm{H}, \mathrm{d}, J=8.0$ $\mathrm{Hz}, \mathrm{H}-2 / 6), 8.11(2 \mathrm{H}, \mathrm{d}, J=8.0 \mathrm{~Hz}, \mathrm{H}-3 / 5), 7.7\left(1 \mathrm{H}, \mathrm{d}, J=7.5 \mathrm{~Hz}, \mathrm{H}-6^{\prime}\right), 7.0\left(1 \mathrm{H}, \mathrm{d}, J=7.0 \mathrm{H}-5^{\prime}\right)$; El-MASS $m / z$, El-MS $m / z$ (\% relative. abundance): $452\left(\mathrm{M}^{+2}, 88\right), 450\left(\mathrm{M}^{+}, 100\right), 332$ (63), 197 (82), 155 (33); Anal. Calculated for $\mathrm{C}_{14} \mathrm{H}_{11} \mathrm{BrN}_{2} \mathrm{O}_{4}$ :(350) C, 47.89; $\mathrm{H}, 3.16 ; \mathrm{Br}, 22.75 ; \mathrm{N}, 7.98 ; 0,18.23$. found: $\mathrm{C}, 47.88 ; \mathrm{H}, 3.18 ; \mathrm{N}$, 7.96.

7.9: (E)-N'-(3-ethoxy-2-hydroxybenzylidene)-4-bromobenzohydrazide.

Chemical formula: $\mathrm{C}_{16} \mathrm{H}_{15} \mathrm{BrN}_{2} \mathrm{O}_{3}$, molecular mass: 362 : Yield: $90 \%$

${ }^{1} \mathrm{H}$ NMR $\left(400 \mathrm{MHz}, \mathrm{DMSO}-\mathrm{d}_{6}\right) \delta 11.76(1 \mathrm{H}, \mathrm{s}, \mathrm{NH}), 8.5(2 \mathrm{H}, \mathrm{d}, J=8.0 \mathrm{~Hz}, \mathrm{H}-2 / 6), 8.47(\mathrm{~s}, 1 \mathrm{H},=\mathrm{CH}), 7.70 .(2 \mathrm{H}$, $\left.\left.\mathrm{t}, J=7.5 \mathrm{~Hz}, \mathrm{H}-3^{\prime \prime} / 5 "\right), 7.73 .(2 \mathrm{H}, \mathrm{d}, J=7.0 \mathrm{~Hz}, \mathrm{H}-3 / 5), 7.53\left(1 \mathrm{H}, \mathrm{d}, J=7.0, \mathrm{H}-6{ }^{\prime}\right), 7.20(1 \mathrm{H}, \mathrm{s}, \mathrm{H}-2)^{\prime}\right), 7.0,(1 \mathrm{H}$, m, $\left.J=7.0 \mathrm{~Hz} \mathrm{H}-5^{\prime}\right), 7.04(2 \mathrm{H}, \mathrm{d}, J=8.0 \mathrm{~Hz}, \mathrm{H}-2 " / 6 "), 7.0(1 \mathrm{H}, \mathrm{t}, J=7.5, \mathrm{H}-4 ")$; El-MAS $m / z$ (\% relative. abundance): $364\left(\mathrm{M}^{+2}, 98\right), 362\left(\mathrm{M}^{+}, 100\right), 298(46), 223$ (73); Anal. Calculated for $\mathrm{C}_{16} \mathrm{H}_{15} \mathrm{BrN}_{2} \mathrm{O}_{3}:(362)$ : C, 52.91; $\mathrm{H}, 4.16 ; \mathrm{Br}, 22.00 ; \mathrm{N}, 7,71 ; 0,13.22$ found: $\mathrm{C}, 52.90 ; \mathrm{H}, 4.19 ; \mathrm{N}, 7,70$.

7.10: (E)-4-bromo-N'-((4-methyl-1H-imidazol-5-yl)methylene)benzohydrazide.

Chemical formula: $\mathrm{C}_{12} \mathrm{H}_{11} \mathrm{BrN}_{4} \mathrm{O}$, molecular mass :362: Yield: $91 \%$.

${ }^{1} \mathrm{H}$ NMR $\left(400 \mathrm{MHz}, \mathrm{DMSO}-\mathrm{d}_{6}\right) \delta 11.56(1 \mathrm{H}, \mathrm{s}, \mathrm{NH}), 8.53(1 \mathrm{H}, \mathrm{s},=\mathrm{CH}), 7.0(\mathrm{~s}, 1 \mathrm{H}, \mathrm{NH}), 8.46(2 \mathrm{H}, \mathrm{d}, \mathrm{J}=7.6 \mathrm{~Hz}, \mathrm{H}-$ 2/6), $8.29(2 \mathrm{H}, \mathrm{d}, J=7.6 \mathrm{~Hz}, \mathrm{H}-3 / 5), 8.16\left(1 \mathrm{H}, \mathrm{d}, J=8.8 \mathrm{~Hz}, \mathrm{H}-3{ }^{\prime}\right), 2.16\left(3 \mathrm{H}, \mathrm{s},-\mathrm{CH}_{3}\right)$; El-MASS $\mathrm{m} / \mathrm{z}(\%$ relative. abundance): $308\left(\mathrm{M}^{+2}, 88\right), 306\left(\mathrm{M}^{+}, 100\right), 149(33), 81$ (58); Anal. Calculated for $\mathrm{C}_{12} \mathrm{H}_{11} \mathrm{BrN}_{4} \mathrm{O}$ : (362): C, 46.93; H, 3.61; Br, 26.01; N, 18.24; 0, 5.21, found: $C, 46.95 ; H, 3.61 ; 18.22$.

1.8.11: (E)-N'-(2,4-dichlorobenzylidene)-4-bromobenzohydrazide.

Chemical formula: $\mathrm{C}_{14} \mathrm{H}_{9} \mathrm{BrCl}_{2} \mathrm{~N}_{2} \mathrm{O}$, molecular mass: 370: Yield: $90 \%$.

${ }^{1} \mathrm{H}$ NMR $\left(400 \mathrm{MHz}, \mathrm{DMSO}_{-} \mathrm{d}_{6}\right) \delta 12.18(\mathrm{~s}, 1 \mathrm{H}, \mathrm{NH}), 8.99(1 \mathrm{H}, \mathrm{s},=\mathrm{CH}), 7.98\left(1 \mathrm{H}, \mathrm{d}, J=7.0 \mathrm{~Hz}, \mathrm{H}-6{ }^{\prime}\right), 7.92(2 \mathrm{H}$, d, $J=8.0 \mathrm{~Hz}, \mathrm{H}-3 / 5), 7.78(2 \mathrm{H}, \mathrm{d}, J=4 \mathrm{~Hz}, \mathrm{H}-2 / 6), 7.70\left(1 \mathrm{H}, \mathrm{s}, \mathrm{H}-3^{\prime}\right), 7.40\left(1 \mathrm{H}, \mathrm{d}, J=7.0 \mathrm{~Hz}, \mathrm{H}-5^{\prime}\right)$; El-MS $\mathrm{m} / \mathrm{z}$ (\% relative. abundance): $374\left(\mathrm{M}^{+4}, 73\right), 372\left(\mathrm{M}^{+2}, 98\right), 370\left(\mathrm{M}^{+}, 100\right), 290$ (87), 213 (55), 78 (39); Anal. Calculated for $\mathrm{C}_{14} \mathrm{H}_{7} \mathrm{BrCl}_{2} \mathrm{~N}_{2} \mathrm{O}$ : (369.9): C, 45.20; $\mathrm{H}, 2.44 ; \mathrm{Br}, 21.48 ; \mathrm{Cl}, 19.06 ; \mathrm{N}, 7.53 ; 0,4.30$. found: $\mathrm{C}$, $45.23 ; \mathrm{H}, 2.42 ; \mathrm{N}, 7.53$. 
7.12: (E)-N'-(3-(benzyloxy)-4-methoxybenzylidene)-4-bromobenzohydrazide.

Chemical formula: $\mathrm{C}_{22} \mathrm{H}_{19} \mathrm{BrN}_{2} \mathrm{O}_{3}$, molecular mass; 438: Yield: $93 \%$.

${ }^{1} \mathrm{H}$ NMR $\left(400 \mathrm{MHz}, \mathrm{DMSO}_{-\mathrm{d}_{6}}\right) \delta, 11.87(1 \mathrm{H}, \mathrm{s}, \mathrm{NH}), 8.45(1 \mathrm{H}, \mathrm{s},=\mathrm{CH}), 7.98(2 \mathrm{H}, \mathrm{d}, J=8.0 \mathrm{~Hz}, \mathrm{H}-3 / 5), 7.86$ $\left(1 \mathrm{H}, \mathrm{s}, \mathrm{H}-6^{\prime}\right), 7.69(2 \mathrm{H}, \mathrm{d}, J=8.5 \mathrm{~Hz}, \mathrm{H}-2 / 6), 7.47\left(1 \mathrm{H}, \mathrm{d}, J=7.0 \mathrm{~Hz}, \mathrm{H}-4^{\prime}\right), 6.95\left(1 \mathrm{H}, \mathrm{d}, J=7.5 \mathrm{~Hz}, \mathrm{H}-3^{\prime}\right), 2.86$ $\left(3 \mathrm{H}, \mathrm{s},-\mathrm{OCH}_{3}\right)$; El-MS $m / z$ (\% relative. abundance): $440\left(\mathrm{M}^{+2}, 98\right), 438\left(\mathrm{M}^{+}, 100\right), 253$ (64) 213 (55); Anal. Calculated for $\mathrm{C}_{22} \mathrm{H}_{19} \mathrm{BrN}_{2} \mathrm{O}_{3}$ : (438.06): $\mathrm{C}, 60.15 ; \mathrm{H}, 4.36 ; \mathrm{Br}, 18.19 \mathrm{~N}, 6.38 ; 0,10.93$,found: $\mathrm{C}, 60.17 ; \mathrm{H}$, $4.36 ; \mathrm{N}, 6.37$

7.13: (E)-N'-(4-hydroxybenzylidene)-4-bromobenzohydrazide.

Chemical formula: $\mathrm{C}_{14} \mathrm{H}_{11} \mathrm{BrN}_{2} \mathrm{O}_{2}$, molecular mass 318: Yield: $92 \%$.

${ }^{1} \mathrm{H}$ NMR $\left(400 \mathrm{MHz}, \mathrm{DMSO}-\mathrm{d}_{6}\right) \delta 12.00(1 \mathrm{H}, \mathrm{s}, \mathrm{NH}), 10.35(1 \mathrm{H}, \mathrm{s},-\mathrm{OH}), 8.36(\mathrm{~s}, 1 \mathrm{H},=\mathrm{CH}), 7.86(2 \mathrm{H}, \mathrm{d}, J=8.0$ $\mathrm{Hz}, \mathrm{H}-3 / 5) 7.73(2 \mathrm{H}, \mathrm{d}, J=8.0 \mathrm{~Hz}, \mathrm{H}-2 / 6), 7.70\left(2 \mathrm{H}, \mathrm{d}, J=7.0 \mathrm{~Hz}, \mathrm{H}-2^{\prime} / 6^{\prime}\right), 6.85\left(2 \mathrm{H}, \mathrm{d}, J=8.0 \mathrm{~Hz}, \mathrm{H}-3^{\prime} / 5^{\prime}\right)$; El-MS m/z (\% relative. abundance): 320 ( $\left.\mathrm{M}^{+2}, 98\right), 318\left(\mathrm{M}^{+}, 100\right), 213$ (55) 197 (48), 155 (33); Anal. Calculated for $\mathrm{C}_{14} \mathrm{H}_{11} \mathrm{BrN}_{2} \mathrm{O}_{2}$ : (318.15): $\mathrm{C}, 52.69 ; \mathrm{H}, 3.37 ; \mathrm{Br}, 25.04 ; \mathrm{N}, 8.78 ; 0,10.03$, found: $\mathrm{C}, 52.72 ; \mathrm{H}$, $3.37 ;$ N, 8.76 .

7.14: (E)-N'-(2,6-dimethoxybenzylidene)-4-bromobenzohydrazide.

Chemical formula: $\mathrm{C}_{16} \mathrm{H}_{15} \mathrm{BrN}_{2} \mathrm{O}_{3}$, molecular mass: 362: Yield 87\%.

${ }^{1} \mathrm{H}$ NMR, (400MHz, DMSO-d 6 ) $\delta 11.53(\mathrm{~s}, 1 \mathrm{H}, \mathrm{NH}), 8.36(\mathrm{~s}, 1 \mathrm{H},=\mathrm{CH}), 8.01(2 \mathrm{H}, \mathrm{d}, J=7.5 \mathrm{~Hz}, \mathrm{H}-2 / 6), 7.69$ $(2 \mathrm{H}, \mathrm{d}, J=7.5 \mathrm{~Hz}, \mathrm{H}-3 / 5), 7.30\left(1 \mathrm{H}, \mathrm{t}, J=8.0 \mathrm{~Hz}, \mathrm{H}-4^{\prime}\right), 6.67\left(2 \mathrm{H}, \mathrm{d}, J=8.0 \mathrm{~Hz}, \mathrm{H}-3^{\prime} / 5^{\prime}\right), 3.83(6 \mathrm{H}, \mathrm{s},-$ $\left.\left(\mathrm{OCH}_{3}\right)_{2}\right)$; El-MS $m / z$ (\% relative. abundance): $364\left(\mathrm{M}^{+2}, 98\right), 362\left(\mathrm{M}^{+}, 100\right), 281$ (87), 213 (55); Anal. Calculated for $\mathrm{C}_{16} \mathrm{H}_{15} \mathrm{BrN}_{2} \mathrm{O}_{3}$ : (362): $\mathrm{C}, 52.91 ; \mathrm{H}, 4.16 ; \mathrm{Br}, 22.00 ; \mathrm{N}, 7.71 ; 0,13.22$, found: $\mathrm{C}, 52.90 ; \mathrm{H}, 4.18$; N, 7.72 .

7.15: (E)-N'-(4-formylbenzylidene)-4-bromobenzohydrazide.

Chemical formula: $\mathrm{C}_{15} \mathrm{H}_{11} \mathrm{BrN}_{2} \mathrm{O}_{2}$, molecular mass: 330: Yield 78\%.

${ }^{1} \mathrm{H}$ NMR $\left(400 \mathrm{MHz}, \mathrm{DMSO}-\mathrm{d}_{6}\right) ; \delta 11.82(1 \mathrm{H}, \mathrm{s}, \mathrm{NH}), 9.97(1 \mathrm{H}, \mathrm{s},-\mathrm{CHO}), 8.35(1 \mathrm{H}, \mathrm{s},=\mathrm{CH}), 8.05(2 \mathrm{H}, \mathrm{d}, J=7.6$ $\left.\mathrm{Hz}, \mathrm{H}-3^{\prime} / 5^{\prime}\right), 8.04\left(2 \mathrm{H}, \mathrm{d}, J=8.0 \mathrm{~Hz}, \mathrm{H}-2^{\prime} / 6^{\prime}\right), 7.95(2 \mathrm{H}, \mathrm{d}, J=8.0 \mathrm{~Hz}, \mathrm{H}-3 / 5), 7.68(2 \mathrm{H}, \mathrm{d}, J=8.8 \mathrm{~Hz}, \mathrm{H}-2 / 6)$; El-MASS $m / z$ (\% relative. abundance): $332\left(\mathrm{M}^{+2}, 98\right), 330\left(\mathrm{M}^{+}, 100\right), 223(75), 213(55) 78$ (26), Anal. Calculated for $\mathrm{C}_{15} \mathrm{H}_{11} \mathrm{BrN}_{2} \mathrm{O}_{2}$ : (330) found: $\mathrm{C}, 54.40 ; \mathrm{H}, 3.35 ; \mathrm{Br}, 24.13 ; \mathrm{N}, 8.46 ; 0,9.66$ : found: $\mathrm{C}, 54.43 ; \mathrm{H}$, $3.35 ; \mathrm{N}, 8.45$.

7.16: (E)-N'-(3,4,5-trimethoxybenzylidene)-4-bromobenzohydrazide. 
Chemical formula: $\mathrm{C}_{17} \mathrm{H}_{17} \mathrm{BrN}_{2} \mathrm{O}_{4}$, molecular mass: 392: Yield 94\%.

${ }^{1} \mathrm{H}$ NMR $\left(400 \mathrm{MHz}, \mathrm{DMSO}-\mathrm{d}_{6}\right) ; \delta 11.46(1 \mathrm{H}, \mathrm{s}, \mathrm{NH}), 8.58(1 \mathrm{H}, \mathrm{s},=\mathrm{CH}), 8.0(2 \mathrm{H}, \mathrm{d}, \mathrm{J}=8.0 \mathrm{~Hz}, \mathrm{H}-3 / 5), 7.88(2 \mathrm{H}$, $\mathrm{d}, J=8.0 \mathrm{~Hz}, \mathrm{H}-2 / 6), 7.0\left(1 \mathrm{H}, \mathrm{s}, \mathrm{H}-2^{\prime} / 6^{\prime}\right), 3.66\left(6 \mathrm{H}, \mathrm{s},\left(\mathrm{OCH}_{3}\right)_{2}\right), 3.66\left(3 \mathrm{H}, \mathrm{s}, \mathrm{OCH}_{3}\right) ; \mathrm{El}-\mathrm{MS} \mathrm{m} / \mathrm{z}$ (\% relative. abundance): $394\left(\mathrm{M}^{+2}, 99\right), 392\left(\mathrm{M}^{+}, 100\right), 361$ (69), 301 (67), 207 (57), 194 (33); Anal. Calculated for $\mathrm{C}_{17} \mathrm{H}_{17} \mathrm{BrN}_{2} \mathrm{O}_{4}$ : (392) C, 51.92; $\mathrm{H}, 4.36 ; \mathrm{Br}, 20.32 ; \mathrm{N}, 7.12 ; \mathrm{O}, 16.27$ : found: $\mathrm{C}, 51.91 ; \mathrm{H}, 4.35 ; \mathrm{N}, 7.12$.

1.8.17: (E)-N'-(3,4-dihydroxybenzylidene)-4-bromobenzohydrazide.

Chemical formula: $\mathrm{C}_{14} \mathrm{H}_{11} \mathrm{BrN}_{2} \mathrm{O}_{3}$, molecular mass: 334: Yield 92\%.

${ }^{1} \mathrm{H}$ NMR $(400 \mathrm{MHz}$, DMSO-d 6 ); $\delta 12.18(1 \mathrm{H}, \mathrm{s}, \mathrm{NH}), 10.75(1 \mathrm{H}, \mathrm{s},-\mathrm{OH}), 8.51(1 \mathrm{H}, \mathrm{s},=\mathrm{CH}) 7.90(2 \mathrm{H}, \mathrm{d}, J=8.8$ $\mathrm{Hz}, \mathrm{H}-2 / 6), 8.02(2 \mathrm{H}, \mathrm{d}, J=8.8 \mathrm{~Hz}, \mathrm{H}-3 / 5), 7.44\left(1 \mathrm{H}, \mathrm{s}, \mathrm{H}-2^{\prime}\right), 7.30\left(1 \mathrm{H}, \mathrm{d}, J=8.0 \mathrm{~Hz}, \mathrm{H}-6^{\prime}\right), 7.0(1 \mathrm{H}, \mathrm{d}, J=8.0$ $\left.\mathrm{Hz}, \mathrm{H}-5^{\prime}\right)$; El-MS $m / z$ (\% relative. abundance): $336\left(\mathrm{M}^{+2}, 98\right), 334\left(\mathrm{M}^{+}, 100\right), 223$ (56), 213 (87), 78 (49); Anal. Calculated for $\mathrm{C}_{14} \mathrm{H}_{11} \mathrm{BrN}_{2} \mathrm{O}_{3}$ : (334) C, 50.17; H, 3.31; Br, 23.84; N, 8.36; O, 14.32: found: $\mathrm{C}, 50.14 ; \mathrm{H}$, $3.33 ; \mathrm{N}, 8.36$.

7.18: (E)-N'-(2,6-dichlorobenzylidene)-4-bromobenzohydrazide.

Chemical formula: $\mathrm{C}_{14} \mathrm{H}_{9} \mathrm{BrCl}_{2} \mathrm{~N}_{2} \mathrm{O}$, molecular mass: 370 : Yield $91 \%$.

${ }^{1} \mathrm{H}$ NMR $(400 \mathrm{MHz}$, DMSO-d 6 ); $\delta 12.18(1 \mathrm{H}, \mathrm{s}, \mathrm{NH}), 8.47(1 \mathrm{H}, \mathrm{s},=\mathrm{CH}), 8.0(2 \mathrm{H}, \mathrm{d}, \mathrm{J}=8.0 \mathrm{~Hz}, \mathrm{H}-2 / 6), 7.70(2 \mathrm{H}$, d, $J=7.0 \mathrm{~Hz}, \mathrm{H}-3 / 5) 7.59\left(1 \mathrm{H}, \mathrm{t}, J=8.0 \mathrm{~Hz}, \mathrm{H}-4^{\prime}\right), 7.48\left(2 \mathrm{H}, \mathrm{d}, J=8, \mathrm{~Hz}, \mathrm{H}-3^{\prime} / 5^{\prime}\right)$; El-MS $\mathrm{m} / \mathrm{z}$ (\% relative. abundance): $374\left(\mathrm{M}^{+4}, 73\right), 372\left(\mathrm{M}^{+2}, 99\right), 372\left(\mathrm{M}^{+}, 100\right), 290$ (78), 223 (23), 213 (55) 197 (59), $188(67)$, 155 (33); Anal. Calculated for $\mathrm{C}_{14} \mathrm{H}_{9} \mathrm{BrCl}_{2} \mathrm{~N}_{2} \mathrm{O}$ : (370): C, 45.20; H, 2.44; $\mathrm{Br}, 21.48 ; \mathrm{Cl}, 19.06 ; \mathrm{N}, 7.53 ; \mathrm{O}, 4.30$ : found: $C, 45.21 ; H, 2.45 ; N, 7.55$.

7.19: (E)-N'-(3-ethoxy-2-hydroxybenzylidene)-4-bromobenzohydrazide.

Chemical formula: $\mathrm{C}_{16} \mathrm{H}_{15} \mathrm{BrN}_{2} \mathrm{O}_{3}$, molecular mass: 362: Yield 93\%.

${ }^{1} \mathrm{H}$ NMR $\left(400 \mathrm{MHz}, \mathrm{DMSO}-\mathrm{d}_{6}\right) ; 811.72(1 \mathrm{H}, \mathrm{s}, \mathrm{NH}), 10.83(1 \mathrm{H}, \mathrm{s},-\mathrm{OH}), 8.16(1 \mathrm{H}, \mathrm{s},=\mathrm{CH}), 8.0(2 \mathrm{H}, \mathrm{d}, J=8.0$ $\mathrm{Hz}, \mathrm{H} 3 / 5), 7.95(2 \mathrm{H}, \mathrm{d}, J=8.0 \mathrm{~Hz}, \mathrm{H}-2 / 6), 7.63\left(1 \mathrm{H}, \mathrm{d}, J=7.0 \mathrm{~Hz}, \mathrm{H}-6^{\prime}\right), 7.5\left(1 \mathrm{H}, \mathrm{d}, J=7.0 \mathrm{~Hz}, \mathrm{H}-4^{\prime}\right), 7.01$ $\left(1 \mathrm{H}, \mathrm{t}, \mathrm{J}=8.0 \mathrm{~Hz}, \mathrm{H}-5^{\prime}\right)$; El-MS $\mathrm{m} / \mathrm{z}$ (\% relative. abundance): $364\left(\mathrm{M}^{+2}, 97\right), 362\left(\mathrm{M}^{+}, 100\right), 316$ (75), 281 (33), 137 (48), 78 (49); Anal. Calculated for $\mathrm{C}_{16} \mathrm{H}_{15} \mathrm{BrN}_{2} \mathrm{O}_{3}$ : (362): C, 52.91; $\mathrm{H}, 4.16 ; \mathrm{Br}, 22.00 ; \mathrm{N}, 7.71 ; 0,13.22$ : found: $\mathrm{C}, 52.91 ; \mathrm{H}, 4.18 ; \mathrm{N}, 7.72$.

7.20: (E)-N'-(2,4-dihydroxybenzylidene)-4-bromobenzohydrazide.

Chemical formula: $\mathrm{C}_{14} \mathrm{H}_{11} \mathrm{BrN}_{2} \mathrm{O}_{3}$, molecular mass: 334: Yield $90 \%$. 
${ }^{1} \mathrm{H}$ NMR $\left(400 \mathrm{MHz}, \mathrm{DMSO}-\mathrm{d}_{6}\right) ; \delta 12.05(1 \mathrm{H}, \mathrm{s}, \mathrm{NH}), 11.45(1 \mathrm{H}, \mathrm{s},-\mathrm{OH}), 10.87(1 \mathrm{H}, \mathrm{s},-\mathrm{OH}), 8.61(1 \mathrm{H}, \mathrm{s},=\mathrm{CH})$, $7.82(2 \mathrm{H}, \mathrm{d}, J=8.0 \mathrm{~Hz}, \mathrm{H}-2 / 6), 7.76(2 \mathrm{H}, \mathrm{d}, J=8.0 \mathrm{~Hz}, \mathrm{H}-3 / 5), 7.51(1 \mathrm{H}, \mathrm{s}, \mathrm{H}-3), 7.48(1 \mathrm{H}, \mathrm{d}, J=7.5 \mathrm{~Hz}, \mathrm{H}-$ $\left.6^{\prime}\right), 7.30\left(1 \mathrm{H}, \mathrm{d}, J=7.5 \mathrm{~Hz}, \mathrm{H}-5^{\prime}\right)$; El-MASS $\mathrm{m} / \mathrm{z}$ (\% relative. abundance): $336\left(\mathrm{M}^{+2}, 97\right), 334\left(\mathrm{M}^{+}, 100\right), 253$ (57), 177 (33), 18 (46); Anal. Calculated for $\mathrm{C}_{14} \mathrm{H}_{11} \mathrm{BrN}_{2} \mathrm{O}_{3}$ : (332): $\mathrm{C}, 50.17 ; \mathrm{H}, 3.31 ; \mathrm{Br}, 23.84 ; \mathrm{N}, 8.36 ; \mathrm{O}$, 14.32: found $C, 50.14 ; H, 3.34 ; N, 8.35$.

7.21: (E)-N'-(anthracen-10-ylmethylene)-4-bromobenzohydrazide.

Chemical formula: $\mathrm{C}_{22} \mathrm{H}_{15} \mathrm{BrN}_{2} \mathrm{O}$, Molecular mass: 402: Yield 89\%.

${ }^{1} \mathrm{H}$ NMR, $\left(400 \mathrm{MHz}, \mathrm{DMSO}-\mathrm{d}_{6}\right) ; \delta 12.25(1 \mathrm{H}, \mathrm{s}, \mathrm{NH}), 8.17(1 \mathrm{H}, \mathrm{s},=\mathrm{CH}), 8.73(1 \mathrm{H}, \mathrm{s}, \mathrm{H}-5), 8.13(2 \mathrm{H}, \mathrm{d}, J=8.0$ $\left.\mathrm{Hz}, \mathrm{H}-4^{\prime} / 6^{\prime}\right), 8.11$ ( $\left.2 \mathrm{H}, \mathrm{d}, J=8.0 \mathrm{~Hz}, \mathrm{H}-1^{\prime} / 9^{\prime}\right)$, 8.07-7.98 (4H, $\left.\mathrm{m}, \mathrm{H}-2 / 6 / 2^{\prime} / 8^{\prime}\right), 7.80-7.73$ (4H, m, H-3/5/3'/4'); El-MASS $m / z$ (\% relative. abundance): 404 ( $\left.\mathrm{M}^{+2}, 97\right), 402\left(\mathrm{M}^{+}, 100\right), 402$ (223), 205 (80), 200 (86), 78 (23). Anal. Calculated for $\mathrm{C}_{22} \mathrm{H}_{15} \mathrm{BrN}_{2} \mathrm{O}$ : (402): $\mathrm{C}, 65.52 ; \mathrm{H}, 3.75 ; \mathrm{Br}, 19.81 ; \mathrm{N}, 6.95 ; 0,3.97$ : found: $\mathrm{C}, 65.53 ; \mathrm{H}$, $3.75 ; \mathrm{N}, 6.97$.

7.22: (E)-N'-(3,5-dichlorobenzylidene)-4-bromobenzohydrazide.

Chemical formula: - $\mathrm{C}_{14} \mathrm{H}_{9} \mathrm{BrCl}_{2} \mathrm{~N}_{2} \mathrm{O}$, molecular mass 370: Yield 94\%.

${ }^{1} \mathrm{H}$ NMR $\left(400 \mathrm{MHz}, \mathrm{DMSO}-\mathrm{d}_{6}\right) ; \delta 11.64(1 \mathrm{H}, \mathrm{s}, \mathrm{NH}), 10.81(1 \mathrm{H}, \mathrm{s},-\mathrm{OH}) 8.49(1 \mathrm{H}, \mathrm{s},=\mathrm{CH}), 8.03(2 \mathrm{H}, \mathrm{d}, \mathrm{J}=8.0$ $\mathrm{Hz}, \mathrm{H}-2 / 6), 7.76(2 \mathrm{H}, \mathrm{d}, J=8.0 \mathrm{~Hz}, \mathrm{H}-3 / 5), 7.54\left(1 \mathrm{H}, \mathrm{s}, \mathrm{H}-4{ }^{\prime}\right), 7.47$ (1H, s, H-6'); El-MS $m / z$ (\% relative. abundance): $374\left(\mathrm{M}^{+4}, 73\right), 372\left(\mathrm{M}^{+2}, 99\right), 372\left(\mathrm{M}^{+}, 100\right), 368$ (47) 349 (28), 314 (23), 229 (45), 155 (39); Anal. Calculated for $\mathrm{C}_{14} \mathrm{H}_{9} \mathrm{BrCl}_{2} \mathrm{~N}_{2} \mathrm{O}$ : (385): $\mathrm{C}, 45.20 ; \mathrm{H}, 2.44 ; \mathrm{Br}, 21.48 ; \mathrm{Cl}, 19.06 ; \mathrm{N}, 7.53 ; \mathrm{O}, 4.30$ : found: $\mathrm{C}$, $45.21 ; \mathrm{H}, 21.49 ; \mathrm{N}, 7.38$.

7.23: (E)-N'-(3-nitrobenzylidene)-4-bromobenzohydrazide.

Chemical formula: $-\mathrm{C}_{14} \mathrm{H}_{10} \mathrm{BrN}_{3} \mathrm{O}_{3}$, molecular mass 347: Yield $91 \%$.

${ }^{1} \mathrm{H}$ NMR $\left(400 \mathrm{MHz}, \mathrm{DMSO}-\mathrm{d}_{6}\right) ; \delta 11.67(1 \mathrm{H}, \mathrm{s}, \mathrm{NH}), 8.90\left(1 \mathrm{H}, \mathrm{t}, J=8.0 \mathrm{~Hz}, \mathrm{H}-5^{\prime}\right), 8.54\left(1 \mathrm{H}, \mathrm{d}, J=8.0 \mathrm{~Hz}, \mathrm{H}-4^{\prime}\right)$, $8.39(1 \mathrm{H}, \mathrm{s},=\mathrm{CH}), 8.00(2 \mathrm{H}, \mathrm{d}, J=8.0 \mathrm{~Hz}, \mathrm{H}-2 / 6), 7.55(2 \mathrm{H}, \mathrm{d}, J=8.0 \mathrm{~Hz}, \mathrm{H}-3 / 5), 8.46(1 \mathrm{H}, \mathrm{d}, J=8.0 \mathrm{~Hz}, \mathrm{H}-$ $\left.6^{\prime}\right), 7.28\left(1 \mathrm{H}, \mathrm{s}, \mathrm{H}-2^{\prime}\right)$; El-MASS $m / z$ (\% relative. abundance): $349\left(\mathrm{M}^{+2}, 98\right), 347\left(\mathrm{M}^{+}, 100\right), 266(65), 223$ (42), 164 (34); Anal. Calculated for $\mathrm{C}_{14} \mathrm{H}_{10} \mathrm{BrN}_{3} \mathrm{O}_{3}$ : (347): C, 48.30; $\mathrm{H}, 2.90 ; \mathrm{Br}, 22.95 ; \mathrm{N}, 12.07 ; 0,13.79$ : found: $\mathrm{C}, 48.32 ; \mathrm{H}, 2.89 ; \mathrm{N}, 12.05$.

7.24: (E)-N'-(2,3,4-trimethoxybenzylidene)-4-bromobenzohydrazide.

Chemical formula: $-\mathrm{C}_{17} \mathrm{H}_{17} \mathrm{BrN}_{2} \mathrm{O}_{4}$, molecular mass 393: Yield 92\%.

${ }^{1} \mathrm{H}$ NMR $\left(400 \mathrm{MHz}, \mathrm{DMSO}-\mathrm{d}_{6}\right) ; \delta 11.68(1 \mathrm{H}, \mathrm{s}, \mathrm{NH}), 8.39(1 \mathrm{H}, \mathrm{s},=\mathrm{CH}), 7.51(2 \mathrm{H}, \mathrm{d}, J=8.0 \mathrm{~Hz}, \mathrm{H}-2 / 6), 7.43$ $(2 \mathrm{H}, \mathrm{d}, J=12 \mathrm{~Hz}, \mathrm{H}-3 / 5), 6.87\left(1 \mathrm{H}, \mathrm{d}, J=8.0 \mathrm{~Hz}, \mathrm{H}-6^{\prime}\right), 6.75\left(1 \mathrm{H}, \mathrm{d}, J=8.0 \mathrm{~Hz}, \mathrm{H}-5{ }^{\prime}\right), 3.97\left(9 \mathrm{H}, \mathrm{s},-\left(\mathrm{OCH}_{3}\right)_{3}\right)$; 
El-MS $m / z$ (\% relative. abundance): $394\left(\mathrm{M}^{+2}, 99.7\right), 392\left(\mathrm{M}^{+}, 100\right), 330$ (66), 311 (59), 300 (61), $166(62)$; Anal. Calculated for $\mathrm{C}_{17} \mathrm{H}_{17} \mathrm{BrN}_{2} \mathrm{O}_{4}$ : (392): $\mathrm{C}, 51.92 ; \mathrm{H}, 4.36 ; \mathrm{Br}, 20.32 ; \mathrm{N}, 7.12 ; 0,16.27$ : found: $\mathrm{C}, 51.93 ; \mathrm{H}$, $4.37 ; \mathrm{N}, 7.16$.

7.25: (E)-N'-(5-bromo-2-hydroxybenzylidene)-4-bromobenzohydrazide.

Chemical formula: $-\mathrm{C}_{14} \mathrm{H}_{10} \mathrm{Br}_{2} \mathrm{~N}_{2} \mathrm{O}_{2}$, molecular mass 396: Yield 89\%.

${ }^{1} \mathrm{H}$ NMR $(400 M H z$, DMSO-d 6 ); $\delta 12.18(1 \mathrm{H}, \mathrm{s},-\mathrm{NH}), 10.67(1 \mathrm{H}, \mathrm{s},-\mathrm{OH}), 8.58(\mathrm{~s}, 1 \mathrm{H},=\mathrm{CH}), 8.15(1 \mathrm{H}, \mathrm{s}, \mathrm{H}-$ $\left.6^{\prime}\right), 8.01(2 \mathrm{H}, \mathrm{d}, \mathrm{J}=8.0 \mathrm{~Hz}, \mathrm{H}-2 / 6), 7.63(2 \mathrm{H}, \mathrm{d}, \mathrm{J}=8.0 \mathrm{~Hz}, \mathrm{H}-3 / 5), 7.61(1 \mathrm{H}, \mathrm{d}, \mathrm{J}=8.0 \mathrm{~Hz}, \mathrm{H}-3 \mathrm{\prime}), 6.98(1 \mathrm{H}, \mathrm{d}, \mathrm{J}$ $\left.=8.0 \mathrm{~Hz}, \mathrm{H}-4^{\prime}\right)$; El-MS $\mathrm{m} / \mathrm{z}$ (\% relative. abundance): $400\left(\mathrm{M}^{+4}, 50\right), 398\left(\mathrm{M}^{+2}, 100\right), 396\left(\mathrm{M}^{+}, 52\right), 314(76)$, 287 (73), 238 (47); Anal. Calculated for $\mathrm{C}_{14} \mathrm{H}_{10} \mathrm{Br}_{2} \mathrm{~N}_{2} \mathrm{O}_{2}$ : (396): C, 42.24; $\mathrm{H}, 2.53 ; \mathrm{Br}, 40.15 ; \mathrm{N}, 7.04 ; 0,8.04$ : found: $\mathrm{C}, 42.25 ; \mathrm{H}, 2.55 ; \mathrm{N}, 7.06$.

7.26: (E)-N'-(2-methylbenzylidene)-4-bromobenzohydrazide.

Chemical formula: $-\mathrm{C}_{15} \mathrm{H}_{13} \mathrm{BrN}_{2} \mathrm{O}$, molecular mass 316: Yield 92\%.

${ }^{1} \mathrm{H}$ NMR $\left(400 \mathrm{MHz}, \mathrm{DMSO}-\mathrm{d}_{6}\right) ; \delta 11.68(1 \mathrm{H}, \mathrm{s}, \mathrm{NH}), 8.71(1 \mathrm{H}, \mathrm{s},=\mathrm{CH}), 8.01(2 \mathrm{H}, \mathrm{d}, \mathrm{J}=8.0 \mathrm{~Hz}, \mathrm{H}-2 / 6), 7.94(2 \mathrm{H}$, d, $J=8.0 \mathrm{~Hz}, \mathrm{H}-3 / 5), 7.61\left(1 \mathrm{H}, \mathrm{d}, J=8.8 \mathrm{~Hz}, \mathrm{H}-6^{\prime}\right), 7.58\left(1 \mathrm{H}, \mathrm{d}, J=8.8 \mathrm{~Hz}, \mathrm{H}-3^{\prime}\right), 7.48\left(1 \mathrm{H}, \mathrm{t}, J=8.8 \mathrm{~Hz}, \mathrm{H}-5^{\prime}\right)$, $7.42\left(1 \mathrm{H}, \mathrm{t}, \mathrm{J}=8.8 \mathrm{~Hz}, \mathrm{H}-4{ }^{\prime}\right), 2.1\left(1 \mathrm{H}, \mathrm{s},-\mathrm{CH}_{3}\right)$; El-MS $\mathrm{m} / \mathrm{z}$ (\% relative. abundance): $398\left(\mathrm{M}^{+2}, 97\right), 396\left(\mathrm{M}^{+}\right.$, 100), 223 (34), 154 (76), 78 (54); Anal. Calculated for $\mathrm{C}_{15} \mathrm{H}_{13} \mathrm{BrN}_{2} \mathrm{O}$ : (316): C, 56.80; H, 4.13; Br, 25.19; N, 8.83 ; $0,5.04$ : found: $C, 56.81 ; H, 4.14 ; \mathrm{N}, 8.84$.

7.27: (E)-N'-(4-methylbenzylidene)-4-bromobenzohydrazide.

Chemical formula: - $\mathrm{C}_{14} \mathrm{H}_{13} \mathrm{BrN}_{2} \mathrm{O}$, molecular mass 316: Yield $88 \%$.

${ }^{1} \mathrm{H}$ NMR (400MHz, DMSO-d $\left.\mathrm{d}_{6}\right) ; \delta 11.98(\mathrm{~s}, 1 \mathrm{H}, \mathrm{NH}), 8.49(\mathrm{~s}, 1 \mathrm{H},=\mathrm{CH}), 8.45(2 \mathrm{H}, \mathrm{d}, J=8.0 \mathrm{~Hz}, \mathrm{H}-3 / 5), 8.29$ $\left(2 \mathrm{H}, \mathrm{d}, J=8.8 \mathrm{~Hz}, \mathrm{H}-2^{\prime} / 6^{\prime}\right), 8.14\left(2 \mathrm{H}, \mathrm{d}, J=8.8 \mathrm{~Hz}, \mathrm{H}-3^{\prime} / 5^{\prime}\right), 7.0(2 \mathrm{H}, \mathrm{d}, J=7.6 \mathrm{~Hz}, \mathrm{H}-2 / 6)$; El-MASS $\mathrm{m} / \mathrm{z}$ (\% relative. abundance): $318\left(\mathrm{M}^{+2}, 97\right), 318\left(\mathrm{M}^{+}, 100\right), 154$ (42), 78 (79); Anal. Calculated for $\mathrm{C}_{15} \mathrm{H}_{11} \mathrm{BrN}_{2} \mathrm{O}$ : (316): C, 56.80; H, 4.13; Br, 25.19; N, 8.83; 0, 5.04: found: C, 56.78; H, 4.13; N, 8.87.

7.28: (E)-N'-benzylidene-4-bromobenzohydrazide.

Chemical formula: - $\mathrm{C}_{14} \mathrm{H}_{11} \mathrm{BrN}_{2} \mathrm{O}$, molecular mass 302: Yield $91 \%$.

${ }^{1} \mathrm{H}$ NMR (400MHz, DMSO-d 6 ); $\delta 12.02(1 \mathrm{H}, \mathrm{s}, \mathrm{NH}), 8.71(1 \mathrm{H}, \mathrm{s},=\mathrm{CH}), 7.91(2 \mathrm{H}, \mathrm{d}, J=8.0 \mathrm{~Hz}, \mathrm{H}-2 / 6), 7.87$ $(2 \mathrm{H}, \mathrm{d}, J=8.0 \mathrm{~Hz}, \mathrm{H}-3 / 5), 7.30\left(5 \mathrm{H}, \mathrm{m}, \mathrm{H}-2^{\prime} / 3^{\prime} / 4^{\prime} / 5^{\prime} / 6^{\prime}\right) ; \mathrm{El}-\mathrm{MS} \mathrm{m} / \mathrm{z}$ (\% relative. abundance): $302\left(\mathrm{M}^{+2}, 97\right)$, 304 ( $\left.\mathrm{M}^{+}, 100\right), 222$ (83), 196 (65), 154 (42); Anal. Calculated for $\mathrm{C}_{14} \mathrm{H}_{11} \mathrm{BrN}_{2} \mathrm{O}$ : (302) found: $\mathrm{C}, 55.47 ; \mathrm{H}$, $3.66 ; \mathrm{Br}, 26.36 ; \mathrm{N}, 9.24 ; 0,5.28$ : found: $\mathrm{C}, 55.48 ; \mathrm{H}, 3.65 ; \mathrm{N}, 9.25$. 
7.29: (E)-N'-(4-(methylthio)benzylidene)-4-bromobenzohydrazide.

Chemical formula: - $\mathrm{C}_{15} \mathrm{H}_{13} \mathrm{BrN}_{2} \mathrm{OS}$, molecular mass 348: Yield 93\%.

${ }^{1} \mathrm{H} \mathrm{NMR}\left(400 \mathrm{MHz}, \mathrm{DMSO}-\mathrm{d}_{6}\right) ; \delta 12.18(\mathrm{~s}, 1 \mathrm{H}, \mathrm{NH}), 8.53(\mathrm{~s}, 1 \mathrm{H},=\mathrm{CH}), 8.15(2 \mathrm{H}, \mathrm{d}, \mathrm{J}=8.0 \mathrm{~Hz}, \mathrm{H}-2 / 6), 7.92(2 \mathrm{H}$, d, $J=8.0 \mathrm{~Hz}, \mathrm{H}-3 / 5), 7.65\left(2 \mathrm{H}, \mathrm{d}, J=8.0 \mathrm{~Hz}, \mathrm{H}-2^{\prime} / 6^{\prime}\right), 7.01\left(2 \mathrm{H}, \mathrm{d}, J=8.0 \mathrm{~Hz}, \mathrm{H}-3^{\prime} / 5^{\prime}\right), 3.02\left(3 \mathrm{H}, \mathrm{s},-\mathrm{SCH}_{3}\right)$; ElMS $m / z$ (\% relative. abundance): $350\left(\mathrm{M}^{+2}, 100\right), 348\left(\mathrm{M}^{+}, 98\right), 223(50), 191$ (62), 78 (29); Anal. Calculated for $\mathrm{C}_{15} \mathrm{H}_{13} \mathrm{BrN}_{2} \mathrm{OS}$ : (348): C, 51.59; H, 3.75; $\mathrm{Br}, 22.88 ; \mathrm{N}, 8.02 ; \mathrm{O}, 4.58 ; \mathrm{S}, 9.18$ : found: $\mathrm{C}, 51.60 ; \mathrm{H}, 3.75 ; \mathrm{N}$, 8.07.

\section{Declarations}

\section{Conflict of Interest.}

The authors have no conflict of interest.

\section{References}

1. Patil S, Jadhav S, Patil U. Natural acid catalyzed synthesis of Schiff base under solvent-free condition: As a green approach. Archives of Applied Science Research. 2012;4(2):1074-8.

2. Berny PJ, de Oliveira LA, Videmann B, Rossi S. Assessment of ruminal degradation, oral bioavailability, and toxic effects of anticoagulant rodenticides in sheep. American journal of veterinary research. 2006;67(2):363-71.

3. Küçükgüzel I, Tatar E, Küçükgüzel ŞG, Rollas S, De Clercq E. Synthesis of some novel thiourea derivatives obtained from 5-[(4-aminophenoxy) methyl]-4-alkyl/aryl-2, 4-dihydro-3H-1, 2, 4-triazole-3thiones and evaluation as antiviral/anti-HIV and anti-tuberculosis agents. European journal of medicinal chemistry. 2008;43(2):381-92.

4. Elder D, Snodin D, Teasdale A. Control and analysis of hydrazine, hydrazides and hydrazonesgenotoxic impurities in active pharmaceutical ingredients (APIs) and drug products. Journal of pharmaceutical and biomedical analysis. 2011;54(5):900-10.

5. Marcano L, Carruyo I, Del Campo A, Montiel X. Cytotoxicity and mode of action of maleic hydrazide in root tips of Allium cepa L. Environmental Research. 2004;94(2):221-6.

6. Kumar P, Narasimhan B, Sharma D, Judge V, Narang R. Hansch analysis of substituted benzoic acid benzylidene/furan-2-yl-methylene hydrazides as antimicrobial agents. European journal of medicinal chemistry. 2009;44(5):1853-63.

7. Yang $\mathrm{Y}-\mathrm{H}$, Shi M. Halogen effects in Robinson-Gabriel type reaction of cyclopropanecarboxylic acid N'-substituted-hydrazides with PPh3/CX4. Tetrahedron letters. 2005;46(37):6285-8.

8. Ragavendran JV, Sriram D, Patel SK, Reddy IV, Bharathwajan N, Stables J, et al. Design and synthesis of anticonvulsants from a combined phthalimide-GABA-anilide and hydrazone pharmacophore. European journal of medicinal chemistry. 2007;42(2):146-51. 
9. Todeschini AR, de Miranda ALP, da Silva KCM, Parrini SC, Barreiro EJ. Synthesis and evaluation of analgesic, antiinflammatory and antiplatelet properties of new 2-pyridylarylhydrazone derivatives. European journal of medicinal chemistry. 1998;33(3):189-99.

10. Gemma S, Kukreja G, Fattorusso C, Persico M, Romano MP, Altarelli M, et al. Synthesis of N1arylidene-N2-quinolyl-and N2-acrydinylhydrazones as potent antimalarial agents active against CQresistant P. falciparum strains. Bioorganic \& medicinal chemistry letters. 2006;16(20):5384-8.

11. Bijev A. New hydrazones as pyrrole derivatives with higher inhibitory activity against Mycobacterium tuberculosis. Lett Drug Des Discov. 2006;3(7):506-12.

12. Gürsoy E, Güzeldemirci NU. Synthesis and primary cytotoxicity evaluation of new imidazo [2, 1-b] thiazole derivatives. European journal of medicinal chemistry. 2007;42(3):320-6.

13. Masunari A, Tavares LC. A new class of nifuroxazide analogues: synthesis of 5-nitrothiophene derivatives with antimicrobial activity against multidrug-resistant Staphylococcus aureus. Bioorganic \& medicinal chemistry. 2007;15(12):4229-36.

14. Loncle C, Brunel JM, Vidal N, Dherbomez M, Letourneux Y. Synthesis and antifungal activity of cholesterol-hydrazone derivatives. European journal of medicinal chemistry. 2004;39(12):1067-71.

15. Küçükgüzel SG, Mazi A, Sahin F, Öztürk S, Stables J. Synthesis and biological activities of diflunisal hydrazide-hydrazones. European journal of medicinal chemistry. 2003;38(11-12):1005-13.

16. Vicini P, Zani F, Cozzini P, Doytchinova I. Hydrazones of 1, 2-benzisothiazole hydrazides: synthesis, antimicrobial activity and QSAR investigations. European journal of medicinal chemistry. 2002;37(7):553-64.

17. Koz'minykh V. Synthesis and biological activity of substituted amides and hydrazides of 1, 4dicarboxylic acids (a review). Pharmaceutical Chemistry Journal. 2006;40(1):8-17.

18. Kidwai M, Kumar R, Srivastava A, Gupta H. Microwave-assisted synthesis of novel 1, 3, 4-thiadiazolylsubstituted 1, 2, 4-triazines as potential antitubercular agents. Bioorganic chemistry. 1998;26(5):28994.

19. Mohammed Khan K, Rahim F, Ambreen N, Taha M, Khan M, Jahan H, et al. Synthesis of benzophenonehydrazone Schiff bases and their in vitro antiglycating activities. Medicinal Chemistry. 2013;9(4):588-95.

20. Mohammed Khan K, Shah Z, Uddin Ahmad V, Khan M, Taha M, Rahim F, et al. Synthesis of 2, 4, 6trichlorophenyl hydrazones and their inhibitory potential against glycation of protein. Medicinal Chemistry. 2011;7(6):572-80.

21. Jamil W, Perveen S, Shah SAA, Taha M, Ismail NH, Perveen S, et al. Phenoxyacetohydrazide Schiff bases: $\beta$-Glucuronidase inhibitors. Molecules. 2014;19(7):8788-802.

22. Mohamad S, Yunus WMZW, Haron MJ, Rahman MZA. Enzymatic synthesis of fatty hydrazides from palm oils. Journal of oleo science. 2008;57(5):263-7.

23. Scavenging DR. Synthesis of benzophenone hydrazone analogs and their DPPH radical scavenging and urease inhibitory activities. J Chem Soc Pak. 2015;37(03):479. 
24. Ahad G, Khan M, Khan A, Ibrahim M, Salar U, Khan KM, et al. Synthesis, structural characterization, and antioxidant activities of 2, 4-dinitrophenyl-hydrazone derivatives. Journal of the Chemical Society of Pakistan. 2018;40(5):961-.

25. Ongay S, Boichenko A, Govorukhina N, Bischoff R. Glycopeptide enrichment and separation for protein glycosylation analysis. Journal of separation science. 2012;35(18):2341-72.

26. Zhang H, Li X-j, Martin DB, Aebersold R. Identification and quantification of N-linked glycoproteins using hydrazide chemistry, stable isotope labeling and mass spectrometry. Nature biotechnology. 2003;21(6):660-6.

27. Hayat M, Khan KM, Saeed S, Salar U, Khan M, Baig T, et al. Antimicrobial activities of synthetic arylidine nicotinic and isonicotinic hydrazones. Letters in Drug Design \& Discovery. 2018;15(10):1057-67.

28. Khan M, Ahad G, Manaf A, Naz R, Hussain SR, Deeba F, et al. Synthesis, in vitro urease inhibitory activity, and molecular docking studies of (perfluorophenyl) hydrazone derivatives. Medicinal Chemistry Research. 2019;28(6):873-83.

29. Priegue JM, Lostalé-Seijo I, Crisan D, Granja JR, Fernández-Trillo F, Montenegro J. Different-length hydrazone activated polymers for plasmid DNA condensation and cellular transfection. Biomacromolecules. 2018;19(7):2638-49.

30. Rubin B, Antonaccio M, Horovitz Z. The Renin-Angiotensin System, Converting Enzyme Inhibition, and Antihypertensive Therapy. Progress in Hormone Biochemistry and Pharmacology: Springer; 1980. p. 1-53.

31. Gomez HJ, Cirillo VJ, Davies RO, Bolognese JA, Walker JF. Enalapril in congestive heart failure: acute and chronic invasive hemodynamic evaluation. International journal of cardiology. 1986;11(1):37-48.

32. Bhattacharjee I, Mazumdar D, Saha SP. Microbial amylases and their potential application in industries: A review. Structure. 2012;18:19-20.

33. Ziyadanoğulları B, Topal G, Erdoğan S, Hamamcı C, Hoşgoren H. Effect of structural modifications of diaza-18-crown-6 on the extractability and selectivity of univalent metal picrates. Talanta. 2001;53(5):1083-7.

34. Avaji PG, Kumar CV, Patil SA, Shivananda K, Nagaraju C. Synthesis, spectral characterization, in-vitro microbiological evaluation and cytotoxic activities of novel macrocyclic bis hydrazone. European Journal of medicinal chemistry. 2009;44(9):3552-9.

35. Yu W, Huang G, Zhang Y, Liu H, Dong L, Yu X, et al. I2-mediated oxidative C-O bond formation for the synthesis of 1, 3, 4-oxadiazoles from aldehydes and hydrazides. The Journal of Organic Chemistry. 2013;78(20):10337-43.

36. Valaparla VK. Purification and properties of a thermostable [alpha]-amylase by acremonium sporosulcatum. International Journal of Biotechnology \& Biochemistry. 2010;6(1):25-35.

37. Ali M, Khan M, Zaman K, Wadood A, Iqbal M, Alam A, et al. Chalcones: As Potent a-amylase Enzyme Inhibitors; Synthesis, In Vitro, and In Silico Studies. Medicinal Chemistry. 2021;17(8):903-12. 


\section{Tables}

Table-1: In vitro $\alpha$-amylase inhibitory activity of synthesized 4-bromobenzohydrazide derivatives (1-30).

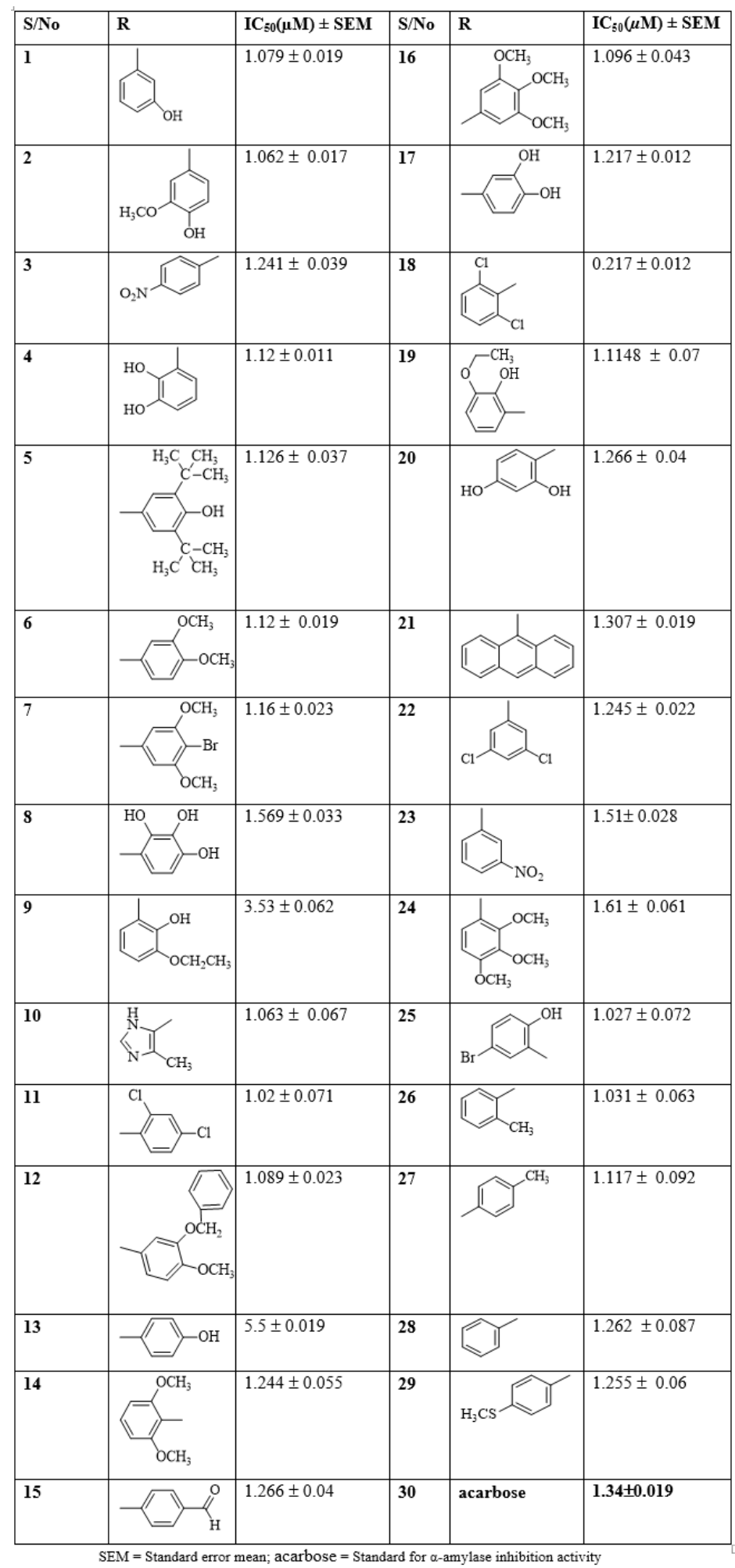

Figures 


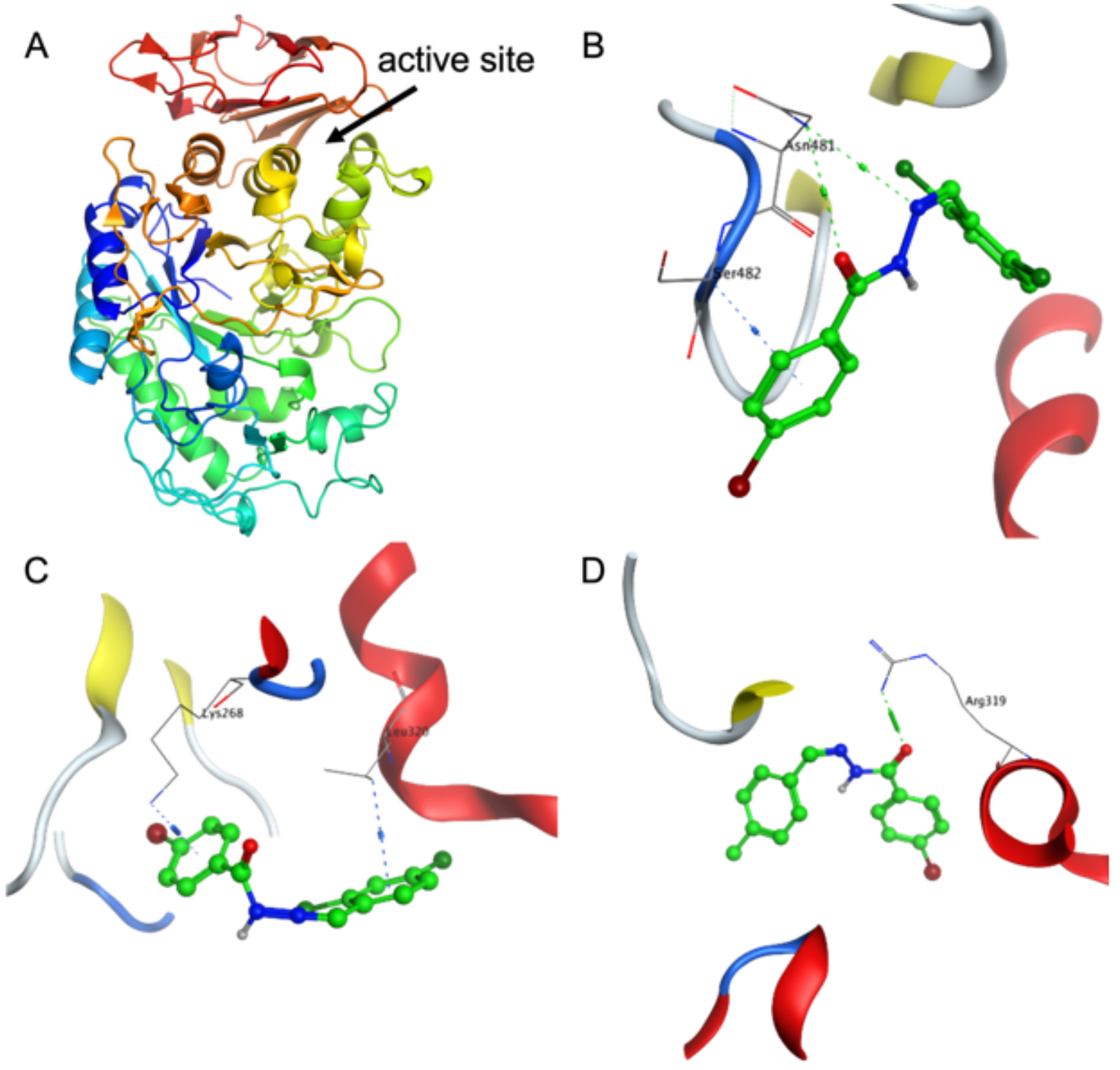

Figure 1

The protein-ligand interaction (PLI) profile for synthesized compounds against a-amylase enzyme. (A) represent the cartonic structure of a-amylase enzyme, B indicate the PLI profile for compound $\mathbf{1 8}, \mathbf{C}$ for compound 11, and $\mathbf{D}$ for compound 27. 